\title{
Pengaruh Pemberian Dana Kapitasi Dengan Motivasi Kerja Dokter Puskesmas di Wilayah Perkotaan di Indonesia
}

\author{
Rusdiana $^{1}$, Ahmad Fickry Faisya ${ }^{2}$ \\ ${ }^{1}$ Megister Kesehatan Masyarakat Universitas Sriwijaya \\ ${ }^{2}$ Fakultas Kesehatan Masyarakat Universitas Sriwijaya \\ Correspondence email: erli.diana@gmail.com
}

\begin{abstract}
Abstrak. Pembagian dana kapitasi mempengaruhi motivasi dan kinerja tenaga kesehatan dalam memberikan pelayanan yang berkualitas di Puskesmas. Motivasi kerja dokter dapat berpengaruh terhadap kualitas pelayanan dan kinerja sumber daya kesehatan yang lainnya. Tujuan penelitian ini adalah untuk mengetahui pengaruh pembagian dana kapitasi terhadap motivasi kerja dokter Puskesmas wilayah perkotaan di Indonesia. Penelitian ini menggunakan data sekunder dari hasil riset Risnakes 2017 dengan disain cross-sectional. Sampel merupakan seluruh dokter di puskesmas di Indonesia yang berhasil diwawancarai dan memiliki variabel independen yang diteliti sebanyak 4.012 sampel. Analisis data dilakukan secara deskriptif dan analitik statistic dengan uji chi-square dan regresi logistic. Dari hasil penelitian didapatkan ada hubungan antara kesesuaian pembagian dana kapitasi dengan motivasi kerja dokter di puskesmas perkotaan di Indonesia dengan $P$ value 0,000 dan PR 1,309 (95\% CI 1,1531,487). Artinya pembagian dan kapitasi yang sesuai memiliki pengaruh 1,309 kali dalam meningkatkan motivasi kerja dokter di puskesmas di indoneisa. Pembagian dana kapitasi harus sesuai dengan beban kerja dokter di puskesmas untuk meningkatkan motivasi dan kinerja pelayanan yang berkualitas di puskesmas dan regulasi yang ada harus dievaluasi secara berkala.
\end{abstract}

Kata kunci : dokter; kapitasi; motivasi kerja; puskesmas

Abstract. The payment of capitation funds affects the motivation and performance of health workers in providing quality services at the Puskesmas. The work motivation of doctors can affect the quality of service and the performance of other health workers. The purpose of this study is to determine the effect of the distribution of capitation funds on the work motivation of doctors in Puskesmas in Indonesia. This study uses secondary data from Risnakes 2017 research results with cross-sectional design. The sample was all doctors in the puskesmas in Indonesia who were successfully interviewed and had independent variables is 4.012 sample. Data analysis was performed descriptively and statistically using chi-square test and logistic regression. From the results of the study found there is a relationship between the suitability of the distribution of capitation funds with the work motivation of doctors in urban health centers in Indonesia with a P value of 0,000 and PR 1,309 (95\% CI 1,153 - 1,487). This means that the appropriate distribution and capitation have an influence of 1,309 times in increasing the work motivation of doctors in Indonesian health centers. The distribution of capitation funds must be in accordance with the workload of doctors at the puskesmas to increase motivation and performance of quality services at the puskesmas and the existing regulations must be regularly evaluated.

Keywords: doctor; capitation; work motivation; public health center

\section{PENDAHULUAN}

Sumber daya manusia merupakan modal dasar pembangunan. Dalam bidang kesehatan, Sumber Daya Manusia Kesehatan (SDM kesehatan) adalah jantung sistem pelayanan kesehatan. Ketersediaan SDM kesehatan yang tidak mencukupi, baik jumlah, jenis, dan kualifikasi serta distribusi yang tidak merata, menimbulkan dampak terhadap rendahnya akses masyarakat terhadap pelayanan kesehatan yang berkualitas (Daniels et al., 2014).

Hasil penelitian yang dilakukan oleh Fery Effendi dan Anna Kurniati yang menemukan bahwa ketersediaan tenaga kesehatan, retensi dan motivasi tenaga kesehatan masih menjadi masalah di Indonesia, hal ini dapat dilihat dari 4 tema besar yaitu finansial insentif, dukungan personal dan professional, pendidikan dan, regulasi (Kurniat et al., 2012).

Retensi dan kualitas suatu pelayanan kesehatan sangat tergantung pada petugas kesehatan yang termotivasi. Motivasi kerja Sumber Daya Manusia Kesehatan (SDMK) berpotensi mempengaruhi pelayanan kesehatan yang diberikan. Moral SDMK yang rendah dapat memperburuk kualitas pelayanan dan menggiring SDMK jauh dari tanggung jawab profesinya. Penelitian menyebutkan bahwa staf yang termotivasi dan berkualitas tinggi merupakan aspek kunci dalam kinerja sistem pelayanan kesehatan (Mutale et al., 2013).

Beberapa penelitian juga menemukan bahwa gaji yang rendah merupakan faktor demotivasi yang paling umum ditemukan, karena tenaga kesehatan merasa keterampilan yang dimiliki tidak dihargai sebagaimana mestinya. Solusi yang sering dilakukan oleh tenaga kesehatan terkait finansial ini adalah dengan berpraktik ganda (bekerja di 2-3 Fasyankes) yang menyebabkan tenaga kesehatan kelebihan beban kerja, kelelahan, dan lain-lain yang menyebabkan kualitas kinerja tenaga kesehatan dalam memberikan pelayanan kesehatan menjadi menurun (Henderson \& Tulloch, 2008) 
Jaminan Kesehatan Nasional (JKN) adalah jaminan berupa perlindungan kesehatan agar peserta memperoleh manfaat pemeliharaan kesehatan dan perlindungan dalam memenuhi kebutuhan dasar kesehatan yang diberikan kepada setiap orang yang telah membayar iuran atau iurannya dibayar oleh pemerintah. Dana Kapitasi adalah besaran pembayaran per-bulan yang dibayar dimuka kepada FKTP berdasarkan jumlah peserta yang terdaftar tanpa memperhitungkan jenis dan jumlah pelayanan kesehatan yang diberikan. Di Indonesia besaran pembagian dana kapitasi dari dana alokasi BPJS di Puskesmas telah diatur berdasarkan Peraturan Menteri Kesehatan Republik Indonesia Nomor 21 Tahun 2016, tentang Penggunaan Dana Kaspitasi Jaminan Kesehatan Nasional Untuk Jasa Pelayanan Kesehatan Dan Dukungan Biaya Operasioanal Pada Fasilitas Kesehatan Tingkat Pertama Milik Pemerintah Daerah pada Bab III Jasa Pelayanan Kesehatan dijelaskan bahwa menurut Pasal 4 ayat (1) Alokasi Dana Kapitasi untuk pembayaran jasa pelayanan kesehatan sebagaimana dimaksud dalam Pasal 3 ayat (2) dimanfaatkan untuk pembayaran jasa pelayanan kesehatan bagi tenaga kesehatan dan tenaga non kesehatan yang melakukan pelayanan pada Fasilitas Kesehatan Tingkat Pertama (FKTP) (Permenkes RI No 21, 2016).

Salah satu tenaga kesehatan yang harus ada di Puskesmas untuk menjamin pelayanan kesehatan di puskemas, adalah dokter (D. Budijanto, 2015). Dokter merupakan penghubung antara sistem kesehatan dan pasien, kinerja dokter sangat berpengaruh pada kinerja organisasi secara keseluruhan. (D'Aunno et al., 2000). Di Indonesia khususnya wilayah perkotaan banyak ditemukan dokter yang berpraktek ganda. Dokter puskesmas bisa berfungsi sebagai klinisi dan dokter praktik mandiri di luar puskesmas. Dokter yang kemungkinan lebih suka bekerja di praktik mandiri daripada di puskesmas dapat berakibat kehilangan waktu untuk melayani pasien di puskesmas. Sebagai akibat dari hal itu, penduduk yang benar-benar datang mencari pertolongan medik di puskesmas dapat dirugikan karena dokter mungkin lebih jarang ditemui di puskesmas.

Pada tahun 2017 persentase rujukan secara nasional dari Fasilitas Kesehatan Tingkat Pertama (FKTP) tercatat 12\% dan pada 2018 angka tersebut naik menjadi $15 \%$, berdasarkan peraturan BPJS Kesehatan No 2 tahun 2015 target indikator zona aman untuk rasio rujukan rawat jalan minimal $<5 \%$. Hal ini berarti bahwa banyak pasien yang dirujuk oleh dokter dari FKTP ke FKTL, padahal target yang diharapkan lebih dari 80 persen permasalahan kesehatan dapat ditangani di tingkat pelayanan primer atau puskesmas(Kemenkes RI, 2018).

Penelitian yang dilakukan di puskesmas Ngeresep Semarang Jawa Tegah menunjukkan bahwa di era BPJS dengan jumlah pasien yang semakin bertambah dan beban kerja yang juga bertambah mengakibatkan prestasi kerja menjadi tidak maksimal sehingga para dokter bekerja tanpa motivasi, ditunjukkan dengan rasio rujukan yang tinggi sebesar $36 \%$. data penyakit yang dirujuk PPK tingkat I ke PPK tingkat II menunjukkan bahwa Puskesmas Ngesrep merujuk pasien dengan penyakit yang dapat ditangani oleh PPK tingkat I seperti DM, Vertigo, Bronkitis dan Presbiopi (Maharanti, 2015).

Penelitian kualitatif yang dilakukan oleh di Puskesmas Walenrang Jawa Tengah mengatakan dilihat dari faktor kedisiplinan, dokter sebagian sering datang tidak tepat waktu, dan kurang puas dengan upah berupa insentif yang diterima. Dari pemantauan juga terlihat bahwa ada dokter yang pulang kerja sebelum waktunya, sehingga pasien tidak mendapat pelayanan kesehatan yang maksimal. (Hartika, 2014)

Berbagai masalah ini didorong banyak faktor, salah satu faktor utama adalah ketidaksesuaian gaji dan harapan. Oleh karena itu pembagian insentif berupa dana kapitasi diharapkan dapat membantu dalam meningkatkan kesejahteraan hidup petugas kesehatan di puskesmas dan membangun motivasi kerja sehingga kinerja dapat dilaksanakan secara maksimal.

Tujuan penelitian ini menganalisi sejauh mana pengaruh pemberian dana kapitasi degan motivasi kerja dokter puskesmas di perkotaan di Indonesia.

\section{METODE}

Desain penelitian ini menggunakan penelitian kuantitatif dengan pendekatan cross-sectional menggunakan data sekunder Riset Ketenagaan di Bidang Kesehatan atau dikenal dengan RISNAKES. Data yang digunakan pada Risnakes penelitian ini yakni data Kuesioner Induk Puskesmas dan Kuesioner Petugas Puskesmas tahun 2017. Populasi dalam penelitian ini adalah seluruh dokter di 9.699 puksemas di Indonesia berdasarkan data Risnakes 2017, jumlah dokter berdasarkan data Risnakes 2017 adalah 20.136. Jumlah sampel bersih yang diperoleh dalam penelitian ini sebanyak 4.012 sampel.

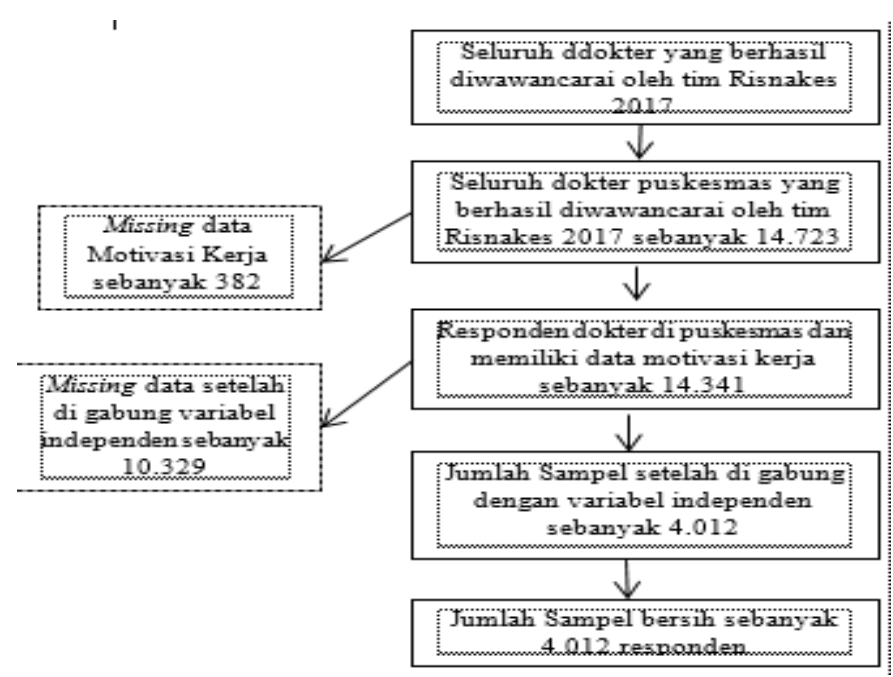

Gambar 1. Alur pemilihan sampel 
Rusdiana dan Ahmad Fickry Faisya, Pengaruh Pemberian Dana Kapitasi Dengan Motivasi Kerja Dokter Puskesmas di Wilayah Perkotaan di Indonesia

Pengumpulan data menggunakan kuesioner yang berisi pertanyaan - pertanyaan yang ditujukan kepada petugas puskesmas yang dilakukan oleh tim petugas Risnakes. Adapun kuesioner yang digunakan dalam Risnakes 2017 kuesioner yang digunakan dalam penelitian ini adalah Kuesioner Puksesmas Induk dan Kuesioner Puskesmas Individu. Data Pada penelitian ini didapatkan dengan cara mengirimkan proposal penelitian ke Laboratorium Manajemen Data Badan Penelitian dan Pengembangan Kesehatan, Kementerian Kesehatan RI.

Analisis dilakukan setelah semua data terkumpul dan telah di input dalam master tabel, data dianalisis menggunakan aplikasi STATA versi 15. Analisis univariat digunakan untuk melihat gambaran karakteristik individu meliputi Faktor Karakteristik indivudu meliputi umur, jenis kelamin, pendidikan, status kawin, dan jabatan, dan pembagian dana kapitasi. Uji chi-square dilakukan untuk mengukur hubungan antara variabel dengan motivasi kerja dokter.

\section{HASIL DAN PEMBAHASAN Analisis Univariat}

Berdasarkan data dari Riset Ketenagaan Di Bidang Kesehatan (Risnakes) Tahun 2017, didapatkan informasi mengenai motivasi kerja dokter di puskesmas wilayah perkotaan didapatkan sebagai berikut :

Tabel 1. Distribusi Frekuensi Motivasi Kerja Dokter Di Puskesmas

\begin{tabular}{ccc}
\hline Motivasi Kerja & $\mathbf{N}$ & Persentase (\%) \\
\hline Rendah & 1.744 & 43,47 \\
Tinggi & 2.268 & 56,53 \\
\hline Total & 4.012 & 100 \\
\hline
\end{tabular}

Berdasarkan Tabel 1 menunjukkan bahwa masih ada dokter yang bekerja di puskesmas di Indonesia memiliki motivasi kerja rendah yaitu sebesar $43,47 \%$.
Tabel 2. Karakteristik responden

\begin{tabular}{lcc}
\hline \multicolumn{1}{c}{ Variabel } & N & Persentase (\%) \\
\hline Umur & & \\
Dibawah 40 thn & 2.353 & 58,65 \\
Diatas sama dengan 40 thn & 1.659 & 41,35 \\
\hline Jenis Kelamin & & \\
Perempuan & 2.988 & 74,48 \\
Laki - laki & 1.024 & 25,52 \\
\hline Pendidikan & & \\
S1 & 3.578 & 89,18 \\
$>$ S1 & 434 & 10,82 \\
Status Kawin & & \\
Tidak Kawin & 330 & 8,23 \\
Kawin & 3.682 & 91,77 \\
\hline Jabatan & & \\
Staf & 3.282 & 81,80 \\
Kepala & 730 & 18,20 \\
\hline Kapitasi & & \\
Dibawah Rp.2.000.000 & 1.943 & 48,43 \\
Sesuai/diatas Rp.2.000.000 & 2.069 & 51,57 \\
\hline
\end{tabular}

Tabel 2 menunjukkan ada $2.988 \quad(74,48 \%)$ responden perempuan dan $1.024(25,52 \%)$ responden laki - laki dengan jumlah terbanyak berumur dibawah 40 tahun $(58,65 \%)$. Mayoritas berpendidikan terakhir sebagai S1 atau dokter umum $3.578(89,18 \%)$ dengan status sudah menikah 3.682 (91,77\%). Dari tabel tersebut juga menunjukkan bahwa sebagian besar responden sebagi staf fungsional dokter biasa 3.282 $(81,8 \%)$ dan mendapatkan pembagian dana kapitasi per bulan sesuai atau diatas Rp. 2.000.000,- sebanyak 2.069 $(51,57 \%)$.

\section{Analisis Bivariat}

Untuk mengetahui ada tidaknya hubungan antara variabel independen dengan variabel dependen maka dilakukan Analisis bivariat. Pada penelitian ini analisis bivariat menggunakan uji chi square karena baik variabel dependen maupun independen merupakan data kategorik.

Tabel 3. Hubungan Pembagian dana Kapitasi denagn Motivasi kerja

\begin{tabular}{|c|c|c|c|c|c|c|}
\hline \multirow{3}{*}{ Variabel } & \multicolumn{4}{|c|}{ Motivasi Kerja } & \multirow[t]{3}{*}{ Pvalue } & \multirow[t]{2}{*}{ PR $(95 \%$ CI $)$} \\
\hline & \multicolumn{2}{|c|}{ Rendah } & \multicolumn{2}{|c|}{ Tinggi } & & \\
\hline & $\mathrm{N}$ & $\%$ & $\mathrm{~N}$ & $\%$ & & \\
\hline Dibawah Rp. 2.000.000,- & 911 & 46,89 & 1.032 & 53,11 & 0,000 & 1,31 \\
\hline Sesuai/ diatas Rp. 2.000.000,- & 833 & 40,26 & .236 & 59,74 & & $(1,15-1,149)$ \\
\hline
\end{tabular}

Berdasarkan hasil temuan bahwa didapatkan bahwa dokter yang dipuskesmas wilayah perkotaan yang mendapatkan pembagian dana kapitasi setiap bulan yang besarannya sesuai atau diatas Rp.2.000.000,- per bulan ada $2.069(51,57 \%)$ orang dan yang mendapatkan pembagian dana kapitasi dibawah Rp.2.000.000,- per bulan ada $1.943(48,43 \%)$ orang. Dilihat dari tabel 3 menunjukkan bahwa ada hubungan yang signifikan antara besaran pemberian dana kapitasi dengan motivasi kerja dokter di puskesmas di perkotaan. Ada 46,89\% dokter yang mendapatkan pembagian dana kapitasi setiap bulan yang besarannya dibawah Rp.2.000.000,memiliki motivasi kerja rendah. Penelitian ini sejalan dengan penelitian yang dilakukan Puskesmas Alai kota Padang Sumatera Barat menyebutkan bahwa ada hubungan bermakna antara disiplin, motivasi, dan pembagian insentif dana kapitasi dengan kinerja pegawai Puskesmas Alai (Essi, 2017). Namun berbeda halnya dengan penelitian yang dilakukan di Puskesmas Metro Lampung mengemukakan bahwa tidak ada hubungan 
yang signifikan antara Insentif dana kapitasi Jaminan Kesehatan Nasional (JKN) dengan motivasi kerja pegawai puskesmas metro, artinya besaran pembagian dana kapitasi JKN tidak mempengaruhi motivasi kerja pegawai (Eldayana, 2015).

Hasil analisis lebih lanjut dari penelitian ini menunjukkan bahwa dokter yang mendapatkan pembagian dana kapitasi diatas Rp.2.000.000,- per bulan akan memiliki motivasi kerja 1,31 kali lebih tinggi dibandingkan yang mendapatkan dibawah itu. Adanya ketidaksesuaian terhadap pembagian insentif dana kapitasi menimbulkan motivasi dan kinerja pegawai turun. Sejalan dengan penelitian yang dilakukan di Puskesmas Walikukun Jawa Timur yang menyebutkan bahwa ada pengaruh pemberian kompensasi yang adil, motivasi dan kepuasan kerja pada dengan kinerja pegawai di Puskesmas Walikukun (Wati et al., 2019).

Kapitasi adalah bentuk insentif yang diberikan oleh puskesmas kepada pegawai puskesmas yang berasal dari dana kapitasi BPJS dengan perhitungan tertentu yang telah ditetapkan. Setiap puskesmas memperoleh dana kapitasi dari Badan Penyelenggara Jaminan Sosial (BPJS) yang dibayar di muka kepada Fasilitas Kesehatan Tingkat Pertama berdasarkan jumlah peserta terdaftar. Insentif keuangan seperti pembagian dana kapitasi di puskesmas yang melaksanakan pelayanan BPJS ini, merupakan salah satu bentuk pembagian jasa pelayaanan dalam meningkatkan pendapatan tenaga kesehatan di puskesmas. Sesuai dengan pemenkes No. 21 tahun 2016, setiap pegawai di puskesmas besaran dana kapitasi yang diterima dihitung berdasarkan jabatan, pendidikan, lama kerja dan tingkat kehadiran sehingga membuat setiap pegawai berbeda besarannya. Di Indonesia besaran rata - rata pembagian dana kapitasi dari alokasi BPJS berbeda- beda di setiap wilayah berdasarkan jumlah peserta terdaftar. Dari data Rinsakes 2017 proporsi terbesar di DKI Jakarta dan yang terendah di Bengkulu. yang terbesar (Risnakes, 2017).

Di wilayah puskesmas perkotaan dokter banyak berpraktek ganda, selain di puskesmas, dokter juga memiliki praktek madiri atau praktek swasta. Dokter bekerja diluar jam kerja sudah diatur oleh peraturan pemerintah nomor 53 tahun 2010 tentang disiplin PNS, selain itu ada juga Permenkes RI nomor 7 tahun 2013 tentang pedoman pengangkatan dan penempatan Dokter dan Bidan tetap serta Permenkes nomor 36 tahun 2014 tentang tenaga kesehatan. Namun sangat disayangkan masih ada dokter yang tidak mematuhi aturan tersebut. Dilihat dengan masih tingginya angka rujukan yang dilakukan FKTP ke FKTL tahun 2018 di Indonesia yaitu sekitar $15 \%$, ini menunjukkan banyak pasien yang tidak terlayani optimal oleh dokter di puskesmas. Ketidakhadiran dan kedisiplinan dokter di puskesmas yang masih tinggi di daerah - daerah tertentu di Indonesia juga menimbulkan dampak serius terhadap pelayanan kesehatan di Puskesmas. Oleh karena itu penting dalam memotivasi kerja dokter untuk meningkatkan pelayanan kesehatan di puskesmas.

Studi yang dilakukan di Kenya menyebutkan bahwa meningkatkan motivasi kerja dokter dan tenaga kesehatan lainnya melalui pemberian insentif lokal yang bersumber dari pelayanan jasa dari fasilitas kesehatan secara tepat dapat menangani harapan tenaga kesehatan dalam hal promosi pekerjaan, penilaian kinerja, dan rasa penghargaan (Mbindyo et al., 2009). Pembagian insentif yang adil dapat meningkatkan motivasi pekerja profesional di puskesmas sehingga dapat mempertahankan pelayanan kesehatan yang baik dan menghindari retensi pegawai di puskesmas. (Ojakaa et al., 2014). Namun dalam hal meningkatkan motivasi kerja membutuhkan perbaikan mekanisme pembayaran dan meningkatkan besaran insentif sesuai dengan beban kerja dan tanggung jawab pegawai masing masing (Khim, 2016).

Pembagian dana kapitasi yang sesuai dengan beban kerja dan tanggung jawab dokter di puskesmas memerankan peranan penting dalam mendorong motivasi kerja dokter di puskesmas. Selain dari pembagian dana kapitasi yang adil dan sesuai dengan regulasi yang ada serta dievaluasi secara berkala, mampu meningkatkan motivasi kerja yang berdampak pada kinerja dokter dalam meberikan pelayanan kesehatan yang berkualitas di puskesmas.

Penelitian ini hanya terbatas rancangan cross sectional yaitu melihat hubungan antara variabel yang diteliti tetapi tidak dapat melihat hubungan sebab akibat. Untuk melihat hubungan berbagai faktor yang memotivasi dan tidak memotivasi kerja dokter puskesmas di Indonesia dengan kinerja pelayanan kesehatan diperlukan analisis komparatif lebih lanjut. Penelitian ini menggunakan data sekunder sehingga hanya meneliti beberapa variabel yang tersedia saja. Masih terdapat banyak variabel/ faktor yang menentukan tingkat motivasi seseorang berdasarkan teori - teori motivasi.

\section{SIMPULAN}

Walaupun bekerja di puskesmas perkotaan dengan sarana dan prasarana yang telah memadai masih ada dokter yang bekerja di puskesmas perkotaan di Indonesia memiliki motivasi kerja rendah yaitu sebesar 43,47\%. Motivasi kerja dokter di puskesmas di wilayah perkotaan harus ditingkatkan agar tidak ada lagi angka rujukan yang tinggi dari puskesmas ke FKTP yang menyebabkan pasien tidak terlayani dengan optimal dan juga untuk meningkatkan kedisiplinan dokter di puskesmas. Salah satu strategi untuk memotivasi dokter di puskesmas perkotaan adalah pemberian dana kapitasi dari alokasi BPJS. Pemberian yang adil sesuai dengan sistem dan regulasi yang ada dapat membangun motivasi kerja sehingga kinerja pelayanan kesehatan dapat dilaksanakan secara maksimal. 
Selain itu pemberian dana kapitasi tersebut harus dievaluasi secara berkala sehingga dalam pembagian tidak ada yang merasa tidak adil. Hal ini akan meningkatkan kepuasan kerja dokter di puskesmas sehingga meningkatnya motivasi kerja dan kinerja dalam memberikan pelayanan kesehatan yang optimal terhadap pasien di puskesmas.

\section{DAFTAR PUSTAKA}

D. Budijanto, W. A. (2015). Tingkat Kecukupan Tenaga Strategis Puskesmas Di Indonesia (Analisis Implementasi Permenkes Number 75 Tahun 2014).

D'Aunno, T., Fottler, MD, \& O'Connor, S. (2000). Motivating People. In Health Care Management, Fourth Edition, (S. Shortell \& and A. Kaluzny, eds.). NY: Delmar.

Daniels, K., Odendaal, W. A., Nkonki, L., Hongoro, C., Colvin, C. J., \& Lewin, S. (2014). Incentives for lay health workers to improve recruitment, retention in service and performance. Cochrane Database of Systematic Reviews, 2014(7). https://doi.org/10.1002/14651858.CD011201

Eldayana, S., Wardiyah, A., Peraturan Menteri Kesehatan No, A., \& Penggunaan Dana Kapitasi Jaminan Kesehatan Nasional Untuk Jasa Pelayanan Kesehatan Dan Dukungan Biaya Operasional Pada Fasilitas Kesehatan Tingkat Pertama, tentang. (2015). Hubungan Insentif Dana Kapitasi Jaminan Kesehatan Nasional (Jkn) Dengan Motivasi Kerja Pegawai Puskesmas Metro Tahun 2014. In ejurnalmalahayati.ac.id (Vol. 9). Retrieved from http://www.ejurnalmalahayati.ac.id/ index.php/holistik/article/download/216/155

Essi, G. (2017). Hubungan Disiplin, Motivasi Kerja dan Pembagian Insentif Dana Kapitasi Program Jaminan Kesehatan Nasional terhadap Kinerja Pegawai Puskesmas Alai Kota Padang Tahun 2017.

Hartika, H. (2014). Motivasi Kerja Tenaga Kesehatan di Puskesmas Walenrang Kabupaten Luwu. 65-70.

Henderson, L. N., \& Tulloch, J. (2008). Incentives for retaining and motivating health workers in Pacific and Asian countries. Human Resources for Health, 6(1), 18. https://doi.org/10.1186/14784491-6-18

Kemenkes RI. Laporan Kesehatan. , (2018).

Khim, K. (2016). Are health workers motivated by income? Job motivation of Cambodian primary health workers implementing performance-based financing. Global Health Action, 9(1), 31068. https://doi.org/10.3402/gha.v9.31068

Kurniati, Anna \& Efendi, F. (2012). Kajian SDM Kesehatan di Indonesia. Jakarta: Salemba Medika.

Maharanti, S. (2015). Motivasi Kerja Dokter pada Era BPJS Kesehatan di Puskesmas Ngeresep Tahun
2015.

Mbindyo, P., Gilson, L., Blaauw, D., \& English, M. (2009). Contextual influences on health worker motivation in district hospitals in Kenya. Implementation Science, $4(1)$. https://doi.org/10.1186/1748-5908-4-43

Mutale, W., Ayles, H., Bond, V., Mwanamwenge, M. T., \& Balabanova, D. (2013). Measuring health workers' motivation in rural health facilities: Baseline results from three study districts in Zambia. Human Resources for Health, 11(1), 1-8. https://doi.org/10.1186/ 1478-4491-11-8

Ojakaa, D., Olango, S., \& Jarvis, J. (2014). Factors affecting motivation and retention of primary health care workers in three disparate regions in Kenya. Human Resources for Health, 12(1), 33. https://doi.org/10.1186/1478-4491-12-33

Permenkes RI No 21. Penggunaan Dana Kaspitasi Jaminan Kesehatan Nasional Untuk Jasa Pelayanan Kesehatan Dan Dukungan Biaya Operasioanal Pada Fasilitas Kesehatan Tingkat Pertama Milik Pemerintah Daerah. , (2016).

Risnakes. (2017). Laporan Riset Ketenagaan di Bidang Kesehatan (RISNAKES) 2017.

Wati, M. R. B., Widayat, W., \& Tjahjono, A. (2019). Pengaruh Kompensasi, Motivasi Dan Kepuasan Kerja Pada Kinerja Pegawai Unit Pelaksana Teknis Puskesmas Walikukun Tahun 2018. 